Article

\title{
Enhancing Flow Field Performance of a Small Circulating Water Channel Based on Porous Grid Plate
}

\author{
Lu Zhang, Xiaobiao Shan and Tao Xie * D
}

State Key Laboratory of Robotics and System, Harbin Institute of Technology, Harbin 150001, China; 18B908080@stu.hit.edu.cn (L.Z.); shanxiaobiao@hit.edu.cn (X.S.)

* Correspondence: xietao@hit.edu.cn

Received: 12 June 2020; Accepted: 22 July 2020; Published: 24 July 2020

check for updates

\begin{abstract}
Low-cost and high-efficiency circulating water channels are widely used in the hydrodynamic tests of an underwater device. The current research mainly focuses on obtaining a better velocity uniformity of the test section by optimizing the curve function of the boundary in the contraction section. While, for small underwater device, their hydrodynamic characteristics are sensitive to turbulence. Thus, the circulating water channel, which can obtain the required turbulence characteristics, is urgently needed. A small circulating water channel, which can reduce the turbulence intensity based on a porous grid plate and can be used to test the hydrodynamic characteristics of a small underwater device, is designed. The relationships between porosities and resistance coefficients of a porous grid plate are established. The effects of the honeycomb (porosity and thickness); screen (porosity, number of layers, and spacing); and pumping flow rate on the turbulent characteristics of the test section are studied. The relationships between the parameters and the turbulent characteristics of the test section are established, and the methods to achieve the required flow characteristics of the test section are proposed. Experiments are carried out, and the validity of the obtained results is verified. In this work, the turbulence intensity of the fluid field in the test section can be restrained to 0.0491 , which is enough to meet the turbulence requirements for the hydrodynamic test of a small underwater device. This work can provide references for the construction of a hydrodynamic test platform for small underwater devices.
\end{abstract}

Keywords: circulating water channel; turbulence intensity; porous grid plate; velocity inhomogeneity

\section{Introduction}

A circulating water channel is one of the important equipments used in hydrodynamic studies [1,2]. The power system, such as the pump, is usually used to drive the water circulation in the water channel, and the tested device is generally positioned in the test section of the channel. Compared with other underwater test systems, the circulating water channel has the advantages of low cost, high efficiency, and quick response. Combined with PIV (particle image velocity) technology, it can effectively observe and record the flow characteristic around the tested equipment [3]. Therefore, a circulating water channel is widely used as an efficient hydrodynamic test system. A circulating water channel can be divided into a horizontal type and vertical type, according to the structural forms. Compared to a horizontal water channel, a vertical water channel can obtain higher efficiency and better flow quality. The actual working environment of the tested device can be simulated by controlling the flow characteristics in the test section.

A circulating water channel system usually includes the power section, suction section, rectification section (including the honeycomb and screens), contraction section, test section, and effluent section. 
The function of the contraction section is to uniformly accelerate the fluid from the rectification section, to ensure that the fluid characteristics in the test section meet the requirements of stability and uniformity [4-6]. The structure of the contraction section is mainly determined by the contraction curve. In order to achieve the required flow characteristics of the test section, researchers have done many studies on the optimization of the contraction curve. The commonly used curves are the Witozinsky curve, Batchelor-Shaw curve, cubic curve, the fifth power curve, etc. [7-9]. Zhou et al. analyzed the influences of several typical contraction curves on the field uniformity in the high-speed water channel [10].

The key components of the rectification section are the porous honeycomb and screen, whose structure size and location parameters have great influences on the flow characteristics of the test section [11]. In normal conditions, these parameters are selected based on experience [12,13]. The honeycomb is mainly used to suppress the lateral turbulence, and the screen is mainly used to suppress the axial turbulence. In order to obtain the required turbulence characteristics of the test section, parameter optimization studies of the honeycomb and screen should be carried out. Lumley and McMahon [12] thought that a large length-diameter ratio of the honeycomb could effectively reduce the turbulence in the downstream fluid field, and the type selecting workflow of the honeycomb was given. Reshotko et al. [14] gave the design methods of the honeycomb and screen based on experience to meet the requirements of controlling the downstream turbulence and noise characteristics. Mikhailova et al. studied the influences of the hole shape of the honeycomb and the position in the wind tunnel on the downstream turbulence characteristics through experiments [15]. Derbunovich et al. optimized the parameters of the screen by the experiments to obtain the required turbulence suppression performance [16,17]. Scheiman and Brooks thought that the turbulence of the downstream fluid field could be reduced by arranging screens at downstream of the honeycomb [18]. Kulkarni [19] compared the flow characteristics under the conditions of a single honeycomb and combining the honeycomb with the screens. The effectiveness of the honeycomb and screens in reducing the turbulent intensity of the fluid field has been proved by the existing research [20-22]. However, the systematic studies of the circulating water tunnel are insufficient. In order to meet the requirements of low turbulence intensity in the test section for a small underwater device, which is sensitive to turbulence, systematic studies on the turbulence reduction of a small circulating water channel based on the honeycomb and screens should be carried out.

In this paper, a small open circulating water channel is designed, and the performance of combining the honeycomb with the screens to reduce the turbulence in the test section is studied. The typical fifth power curve is adopted as the curve of the boundary in the contraction section contraction. The designed water channel can be used to study the hydrodynamic characteristics of the small equipment. The relationships between porosity, viscosity resistance coefficient, and inertia resistance coefficient have been established. The effects of the thickness and porosity of the honeycomb and porosity, layer numbers, and spacing of the screen on the turbulent characteristics and velocity nonuniformity of the test section are analyzed. Meanwhile, the influences of the pumping flow rate on the turbulent characteristics and flow characteristics of the test section are studied. Based on the obtained results, the methods to obtain the required fluid field characteristics of the test section were proposed, and a circulating water tunnel was established for the experiments. Experiments were carried out to verify the obtained theoretical results and proposed methods.

\section{Structure and Working Principle}

The small circulating water channel designed in this work adopts the type of a vertical form, and the power section is under the water channel. The hydrodynamic characteristics of the underwater device in the axial direction ( $x$ direction) and lateral direction ( $y$ direction) can be tested by a flow rate meter or by using PIV testing technology. Figure 1 shows the structure and fundamental dimensions of the circulating water channel. The power section mainly relies on the water pump to pump the fluid with a rated flow. The suction section transmits the pumped fluid to the rectification section. 
In the rectification section, the honeycomb and screen are used to suppress the axial and lateral turbulence. The contraction section uniformly accelerates the fluid from the rectification section to the test section, depending on the specific boundary curve. The flow characteristics of the test section are stable and uniform, which are suitable for the simulation of the actual underwater working environment of the tested device. The effluent section leads the fluid from the test section to the power section to complete the whole circulation process. The wall of the test section is made of acrylic plate with high transmittance, so the fluid field characteristics of the $x-y$ section and $x-z$ section can be measured by PIV technology. The PIV system mainly includes a tracer particle, laser generator, and an image acquisition and image-processing method. The tracer particles are uniformly distributed in the measured fluid domain, the laser is emitted at the observed position, and particle images at different times are collected by a CCD (charge coupled device) camera and processed by the image-processing method. The characteristics of the measured fluid domain can be obtained after the image processing. The particle motion data is mainly obtained by the CCD camera; the size of the tracer particle should be larger than the single pixel of the camera. The effective measurement range depends on the accuracy and location of the CCD camera. It can be seen that a better test performance can be obtained by using a camera with high resolution, which also increases the cost as well. Besides, as the main raw test data of the PIV system is the particle position, when the PIV system is applied to the mixture fluid with a high concentration of the dispersed phase, the test performance has substantial limitations. More details about establishing the PIV visualization technology can be found in the works of Jakubowski et al. [23,24].

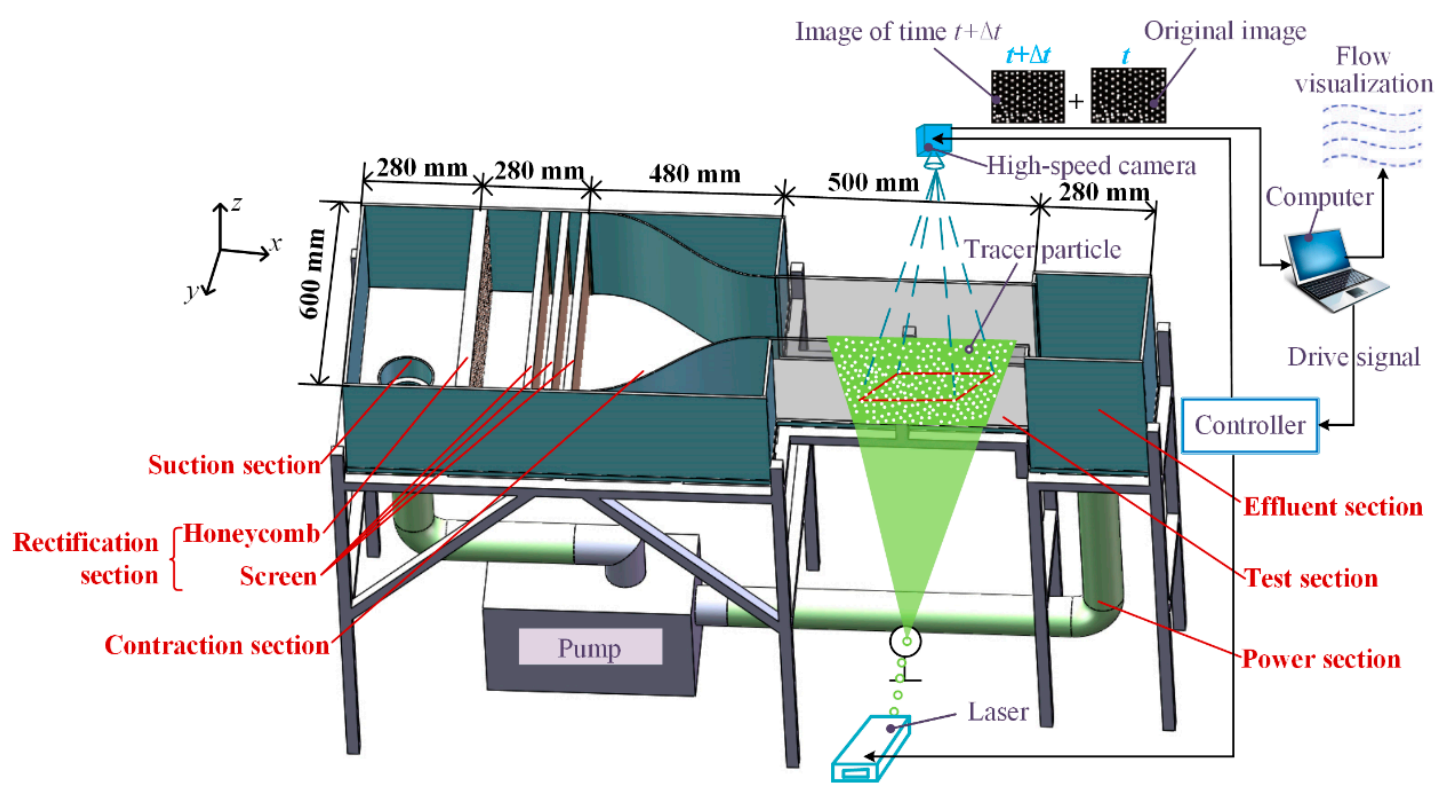

Figure 1. Structure diagram of the designed circulating water channel.

The boundary of the contraction section, which is located between the rectification section and the test section, is a smooth curve. The cross-sectional area of the contraction section decreases along the flow direction according to certain rules, so as to increase the flow speed uniformly. In this work, the fifth power curve is selected as the contraction curve, as shown in Figure 2. When using this curve, fluid separation is not easy to be produced at the entrance, and the energy loss is less than selecting other curves [10]. The curve equation can be described as:

$$
\frac{R-R_{2}}{R_{1}-R_{2}}=1-10\left(\frac{x}{L}\right)^{3}+15\left(\frac{x}{L}\right)^{4}-6\left(\frac{x}{L}\right)^{5}
$$


where $R_{1}$ is the radius at the inlet of the contraction section, $R_{2}$ is the radius at the outlet, $L$ is the length of the contraction section, and $R$ is the radius at a location where the distance from the inlet is $x$.

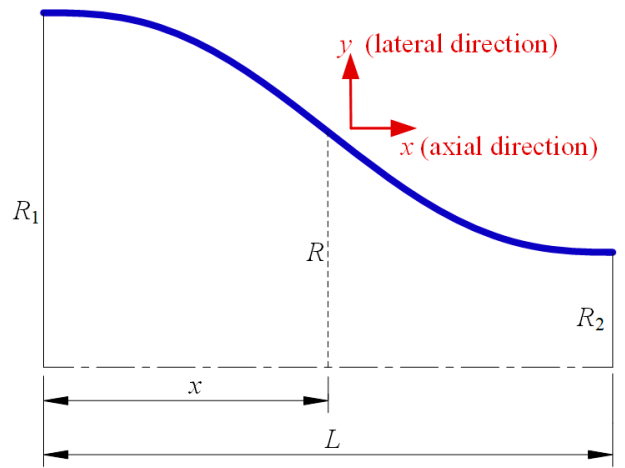

Figure 2. The selected contraction curve. $R_{1}$ is the radius at the inlet of the contraction section, $R_{2}$ is the radius at the outlet, $L$ is the length of the contraction section, and $R$ is the radius at a location where the distance from the inlet is $x$.

Considering the overall occupancy space and cost of the circulating water channel, the length of the contraction section should not be too long [25]. The contraction ratio of the contraction section is described as $C=\left(R_{1} / R_{2}\right)^{2}$, and the turbulence intensity is inversely proportional to the contraction ratio. In order to reduce the turbulence intensity, the contraction ratio needs to be larger [26,27]. In this work, the length of the contraction section is $480 \mathrm{~mm}$, the contraction ratio is 9 .

\section{Resistance Coefficient of a Porous Grid Plate}

In order to improve the uniformity of the velocity and pressure distribution of the fluid flowing to the contraction section, a porous grid plate should be placed in the rectification section to improve the flow quality [18]. The porous grid plate in the rectification section mainly includes the honeycomb and screens. In general, the honeycomb with a relatively large thickness is selected to suppress the lateral turbulence, and the screen with a little thickness is selected to suppress the axial turbulence. The screens are arranged at certain intervals, as shown in Figure 3, where $d$ represents the spacing between the screens, and $l$ represents the thickness of the honeycomb.

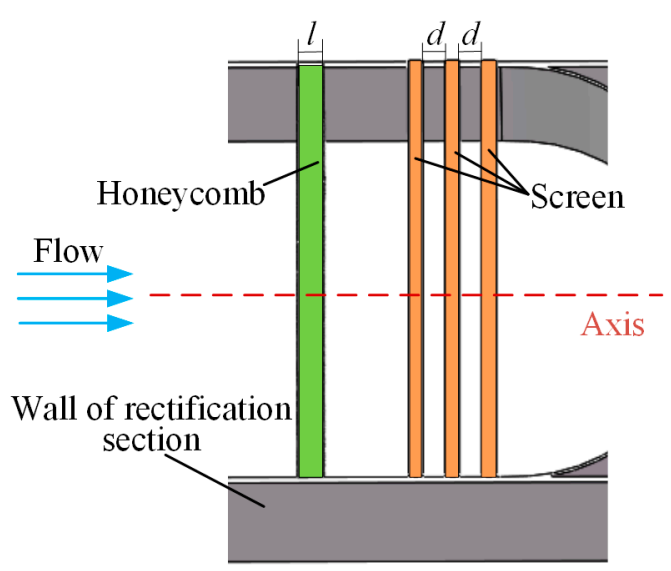

Figure 3. Local parameters of the rectification section. $d$ represents the spacing between the screens, and $l$ represents the thickness of the honeycomb.

When flowing through the porous grid plate, the fluid is rectified by the holes to flow along the axial direction. When the fluid flows through the hole, it will be subject to the viscous resistance and inertial resistance. In order to study the rectification characteristics of the designed circulating 
water channel based on the porous grid plate with different porosities, it is necessary to obtain the viscosity resistance coefficients and inertia resistance coefficients of the porous grid plate with different porosities. Computational fluid dynamics (CFD) is mainly used for simulating the fluid characteristics; researchers can use self-built models to achieve fast and accurate CFD calculations or take use of commercial finite element analysis software such as Fluent or CFX. Jakubowski et al. [28] built a three-phase Volume of Fluid (VOF) model to predict the sedimentation and accumulation of sediment and obtained well accuracy. The main purpose of this work is to analyze the rectification performance by a porous grid plate, and the finite element analysis software Fluent is mainly used in this work. When the fluid flows into the porous grid plate, the loss of the momentum source includes two parts: viscous loss and inertia loss, which can be described as [29]:

$$
\frac{\Delta P}{\Delta \delta}=-S=\frac{\mu}{\alpha} v+\frac{C_{2}}{2} \rho v^{2}
$$

where $\Delta P$ is the pressure drop generated when the fluid flows through a porous grid plate with a thickness of $\Delta \delta, S$ is momentum, $v$ is velocity, $\mu$ is viscosity, $\rho$ is density, $1 / \alpha$ is the viscosity resistance coefficient, and $C_{2}$ is the inertia resistance coefficient.

It can be seen from Formula (2) that the viscosity resistance coefficient and inertia resistance coefficient are related to the porosity of the porous grid plate but not to its thickness. A test model for obtaining the resistance coefficients is shown in Figure 4; in order to facilitate the calculating, the diameters and spacing of the holes are taken as finite decimals, which results in the porosities are infinite decimals. Generally, the porosity of a porous grid plate is between 0.5 and 0.7 . The results of the velocity $v$ and $\Delta P / \Delta \delta$ of fluid flowing through porous grid plates with different porosities are obtained, and the corresponding viscosity resistance coefficient $1 / \alpha$ and inertia resistance coefficient $C_{2}$ are calculated by quadratic fitting, as shown in Table 1.

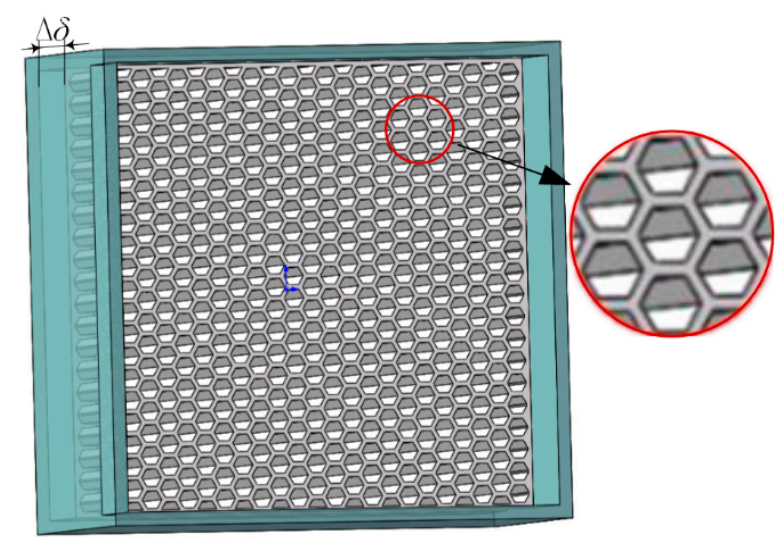

Figure 4. The test model of a porous grid plate. $\Delta \delta$ : thickness of the porous grid plate. 
Table 1. The obtained resistance coefficients. $\Delta P$ : pressure drop generated when the fluid flows through a porous grid plate and $\Delta \delta$ : thickness of the porous grid plate.

\begin{tabular}{|c|c|c|c|c|c|}
\hline Porosity & Velocity (m/s) & Pressure Drop (Pa) & Fitting Equation & Viscous Resistance Coefficient & Inertial Resistance Coefficient \\
\hline \multirow{5}{*}{0.5026} & 0.5 & 407.78 & \multirow{5}{*}{$\Delta P / \Delta \delta=1511.1 v^{2}+85.999 v$} & \multirow{5}{*}{$4.3 \times 10^{7}$} & \multirow{5}{*}{1511.1} \\
\hline & 1 & 1638.6 & & & \\
\hline & 1.5 & 3468.1 & & & \\
\hline & 2 & 6258.1 & & & \\
\hline & 2.5 & 9648.1 & & & \\
\hline \multirow{5}{*}{0.6013} & 0.5 & 265.66 & \multirow{5}{*}{$\Delta P / \Delta \delta=726 v^{2}+303.1 v$} & \multirow{5}{*}{$1.51 \times 10^{8}$} & \multirow{5}{*}{726} \\
\hline & 1 & 1008.6 & & & \\
\hline & 1.5 & 2158.3 & & & \\
\hline & 2 & 3503.1 & & & \\
\hline & 2.5 & 5280.5 & & & \\
\hline \multirow{5}{*}{0.6361} & 0.5 & 245.59 & \multirow{5}{*}{$\Delta P / \Delta \delta=575.27 v^{2}+322.04 v$} & \multirow{5}{*}{$1.61 \times 10^{8}$} & \multirow{5}{*}{575.27} \\
\hline & 1 & 884.3 & & & \\
\hline & 1.5 & 1850.1 & & & \\
\hline & 2 & 2914.9 & & & \\
\hline & 2.5 & 4398.2 & & & \\
\hline \multirow{5}{*}{0.6599} & 0.5 & 247.56 & \multirow{5}{*}{$\Delta P / \Delta \delta=521.02 v^{2}+344.31 v$} & \multirow{5}{*}{$1.72 \times 10^{8}$} & \multirow{5}{*}{521.02} \\
\hline & 1 & 859.63 & & & \\
\hline & 1.5 & 1753.6 & & & \\
\hline & 2 & 2738.9 & & & \\
\hline & 2.5 & 4118.6 & & & \\
\hline \multirow{5}{*}{0.7088} & 0.5 & 344.95 & \multirow{5}{*}{$\Delta P / \Delta \delta=502.29 v^{2}+564.25 v$} & \multirow{5}{*}{$2.82 \times 10^{8}$} & \multirow{5}{*}{502.29} \\
\hline & 1 & 1055.1 & & & \\
\hline & 1.5 & 2050 & & & \\
\hline & 2 & 3107.3 & & & \\
\hline & 2.5 & 4547.2 & & & \\
\hline
\end{tabular}




\section{Discussions of the Fluid Field Characteristics}

The state of the fluid field with the rectification of the honeycomb and screens is shown in Figure 5. It can be observed that the honeycomb and the screen can effectively restrain the turbulence and improve the velocity uniformity of the fluid. The key parameters that affect the rectification performance of the rectification section are the thickness $l$ and porosity $q_{1}$ of the honeycomb, the porosity $q_{2}$, the number of layers $n$, and the spacing $d$ of the screen. Therefore, the influences of the parameters of the rectification section on the flow characteristics of the test section have been studied. The single variable principle is adopted in the analyses - that is, when the influences of a single parameter are analyzed, other parameters remain unchanged. The initial values of the parameters are shown in Table 2. In order to obtain the accuracy results, the hexahedron element sizes were set less than $7 \mathrm{~mm}$ in the meshing process, and more than 300,000 elements were obtained. Before the calculations, we tested the mesh quality and found the minimum orthogonal quality was more than 0.2 and maximum ortho skew was less than 0.05 , which could meet the requirements. The $k$-epsilon with standard wall functions were applied as the viscous model, and the Pressure-Implicit with Splitting of Operators (PISO) algorithm with neighbor correction were chosen for the calculations.

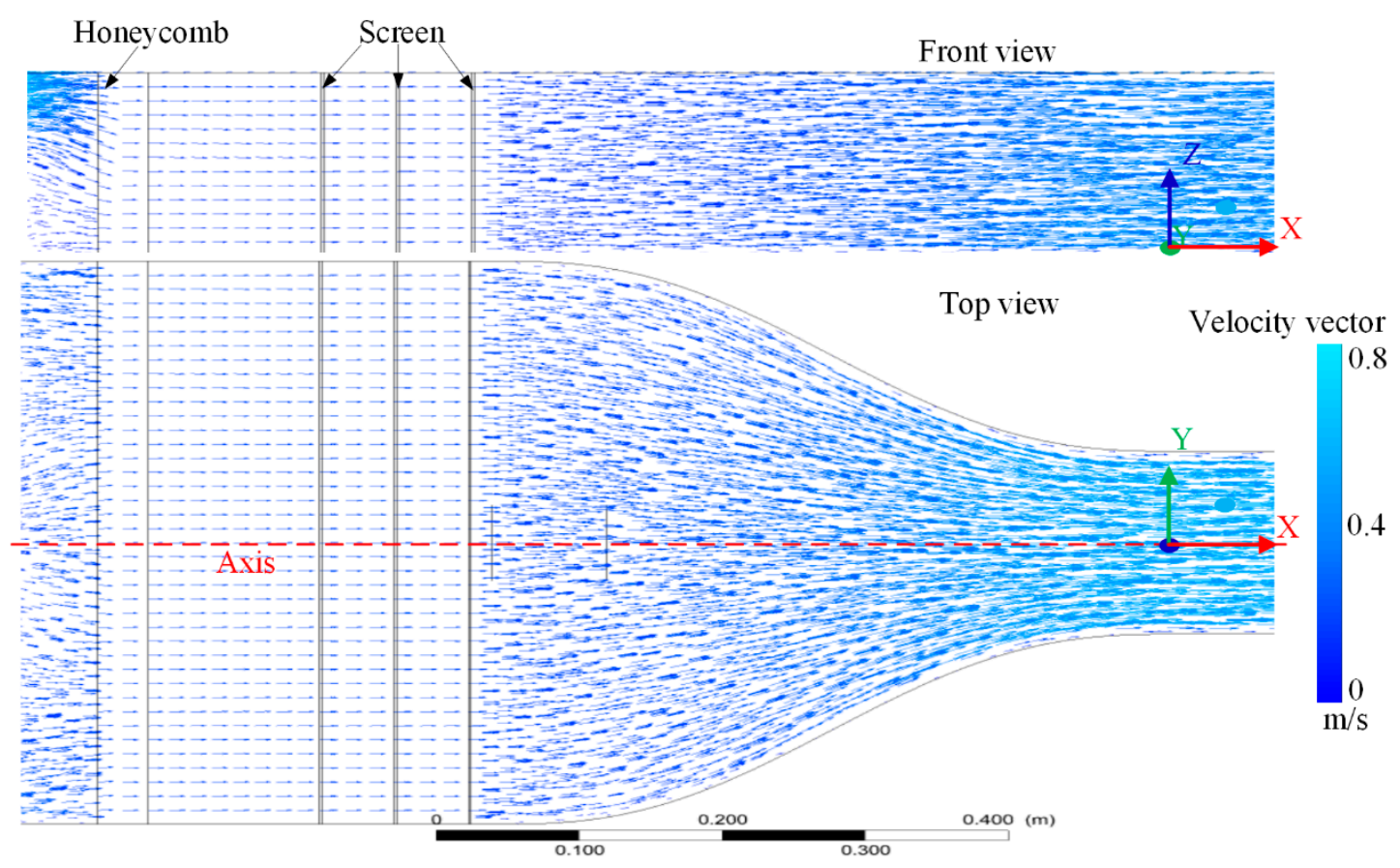

Figure 5. The state of the fluid field with the rectification of the honeycomb and screens.

Table 2. The initial values of the parameters.

\begin{tabular}{ccc}
\hline & Parameter & Initial Value \\
\hline \multirow{2}{*}{ Honeycomb } & Thickness $l$ & $35 \mathrm{~mm}$ \\
& Porosity $q_{1}$ & 0.6361 \\
\hline \multirow{2}{*}{ Screen } & Porosity $q_{2}$ & 0.6361 \\
& Number of layers $n$ & 3 \\
& Spacing $d$ & $50 \mathrm{~mm}$ \\
\hline & Pumping flow rate $Q$ & $5 \mathrm{~kg} / \mathrm{s}$ \\
\hline
\end{tabular}




\subsection{Influences of the Honeycomb}

\subsubsection{Influences of the Honeycomb Thickness $l$}

The large thickness of the honeycomb can obtain a better turbulence reduction performance of the lateral flow; however, the increase of the thickness will lead to the increase of the internal friction loss. In order to obtain the appropriate thickness of the honeycomb, we studied the fluid field characteristics of the test section with the honeycomb when different thicknesses were applied.

Figure 6 shows the velocity distribution characteristics of the fluid field from the inlet $(x=0 \mathrm{~m})$ to the outlet $(x=0.5 \mathrm{~m}$ ) of the test section, when the honeycomb with different thicknesses is selected. It can be observed that, when the thickness of the honeycomb is $35 \mathrm{~mm}$, the velocity fluctuation of the fluid field in the test section is smaller, and the velocity distribution is more uniform. Figure 7 shows the distribution of the turbulence intensity when the honeycomb with different thicknesses is selected. Figure $7 \mathrm{a}$ shows the turbulence intensity along the axial direction from the inlet $(x=0 \mathrm{~m})$ to the outlet $(x=0.5 \mathrm{~m})$ of the test section, and Figure $7 \mathrm{~b}$ shows the turbulence intensity along the lateral direction on the middle area $(x=0.25 \mathrm{~m})$ of the test section. It can be seen that the turbulence intensity decreases gradually along the axial direction. The turbulence intensity at the center line of the water channel is the largest and decreases symmetrically to both sides. The area with the uniform turbulence intensity is mainly concentrated near the center line $(-0.02 \mathrm{~m}<y<0.02 \mathrm{~m})$ of the test section. The smallest turbulence intensity can be obtained when the honeycomb with the thickness as $35 \mathrm{~mm}$ is selected in this work.

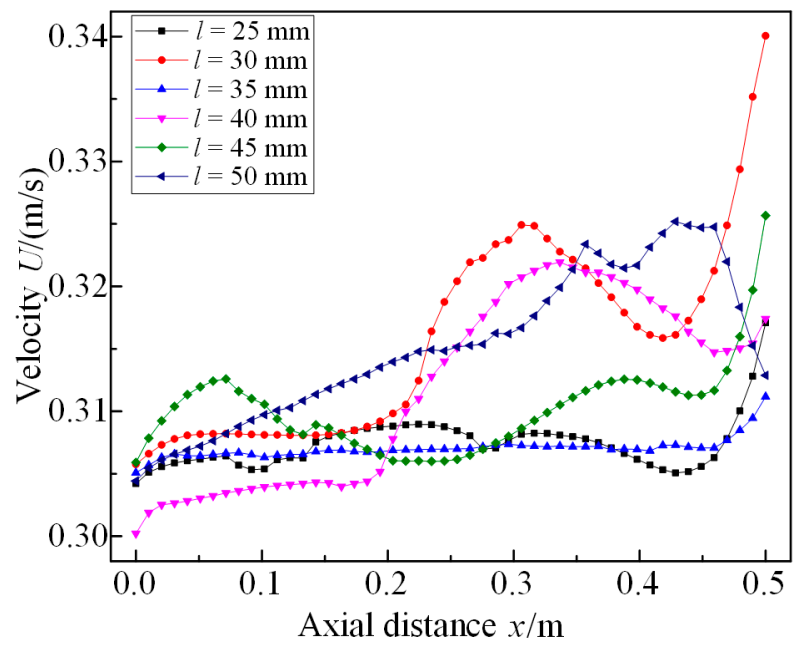

Figure 6. The velocity distribution characteristics of the fluid field from the inlet to the outlet of the test section when the honeycomb with different thicknesses is selected. 

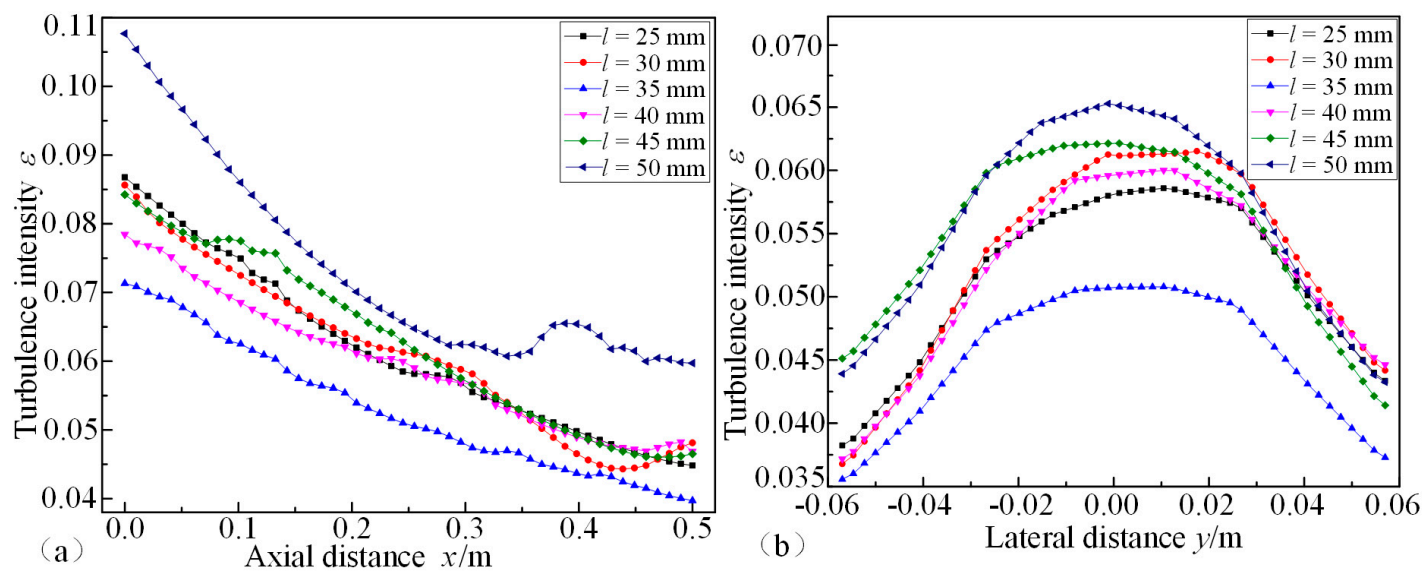

Figure 7. The distribution of the turbulence intensity when the honeycomb with different thicknesses is selected: (a) along the axial direction and (b) along the lateral direction.

The velocity inhomogeneity is defined as

$$
\beta=\frac{U_{\max }-U_{\min }}{U}
$$

where $U_{\max }$ is the maximum velocity, $U_{\min }$ is the minimum velocity, and $U$ is the mean velocity.

Table 3 shows the velocity inhomogeneity and average turbulence intensity of the fluid field in the test section when the honeycomb with different thicknesses is selected. It can be seen that, with the increase of the thickness of the honeycomb, the velocity inhomogeneity and the average turbulence intensity decrease before $35 \mathrm{~mm}$ and then increase gradually.

Table 3. The velocity inhomogeneity and average turbulence intensity of the fluid field in the test section when the honeycomb with different thicknesses is selected.

\begin{tabular}{ccccccc}
\hline Thickness & $\mathbf{2 5} \mathbf{~ m m}$ & $\mathbf{3 0} \mathbf{~ m m}$ & $\mathbf{3 5} \mathbf{~ m m}$ & $\mathbf{4 0} \mathbf{~ m m}$ & $\mathbf{4 5} \mathbf{~} \mathbf{m}$ & $\mathbf{5 0} \mathbf{~ m m}$ \\
\hline Velocity inhomogeneity $\beta$ & 1.2198 & 1.2032 & 1.1240 & 1.1514 & 1.1531 & 1.1542 \\
Average turbulence intensity & 0.0564 & 0.0561 & 0.0491 & 0.0544 & 0.0573 & 0.0649 \\
\hline
\end{tabular}

Figure 8 shows the velocity contour of the fluid field in the middle section $(z=0.015 \mathrm{~m})$ of the test section when the honeycomb with different thicknesses is selected. It can be seen that the velocity presents a gradient trend from the two sides to the center. The results show that the velocity distribution of the fluid field in the test section is relatively more uniform when the honeycomb with the thickness as $35 \mathrm{~mm}$ is selected. Therefore, in order to obtain the fluid field with a uniform velocity and low turbulence intensity, the intermediate thickness of the honeycomb should be selected. In this work, when the thickness of the honeycomb is $35 \mathrm{~mm}$, the appropriate flow characteristics can be obtained. 


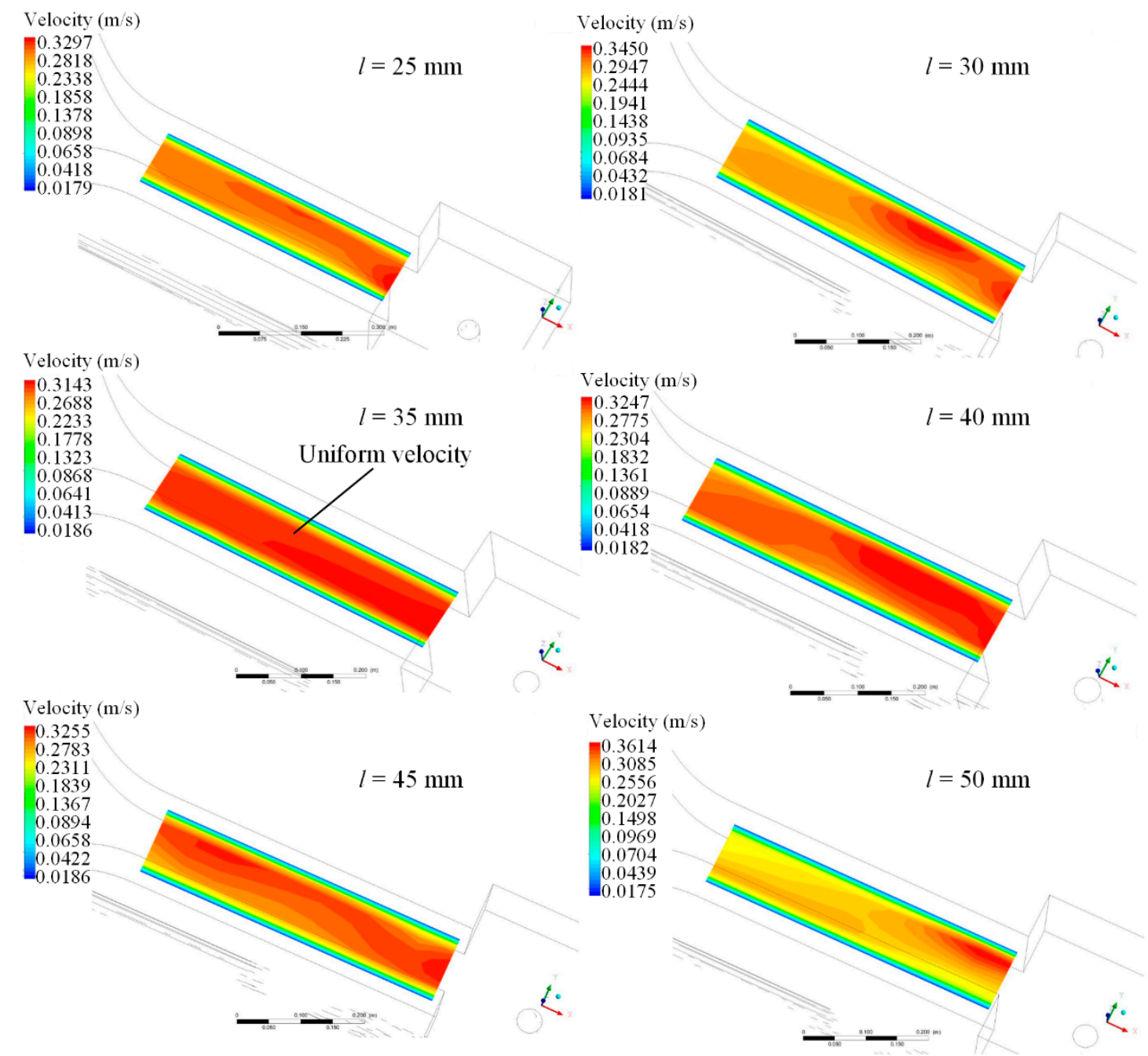

Figure 8. The velocity contour of the fluid field in the middle section $(z=0.015 \mathrm{~m})$ when the honeycomb with different thicknesses is selected.

\subsubsection{Influences of the Honeycomb Porosity $q_{1}$}

The rectifying characteristics of the honeycomb are mainly related to the porosity but not to the shape of the honeycomb (circle, hexagon, and square) [19]. When the honeycomb with the thickness as $35 \mathrm{~mm}$ is selected, the influences of porosity on the flow characteristics are studied. Figure 9 shows the velocity distribution statuses of the fluid field from the inlet $(x=0 \mathrm{~m})$ to the outlet $(x=0.5 \mathrm{~m})$ of the test section, when the honeycomb has different porosities. As can be seen from Figure 9 , the uniform velocity distribution can be obtained in the region from $x=0.05 \mathrm{~m}$ to $0.35 \mathrm{~m}$. Figure 10 displays the distribution characteristics of the turbulence intensity on the middle area $(x=0.25 \mathrm{~m})$ of the test section when the honeycomb with different porosities are used. The turbulence intensity results along the axial direction and lateral direction of the test section are shown in Figure 10a,b respectively. Table 4 shows the velocity inhomogeneity and average turbulence intensity of the fluid field in the test section when the honeycomb with different porosities is applied. The results show that, with the increase of the porosity, the velocity inhomogeneity and the average turbulence intensity of the test section decrease to a certain value and then increase gradually. 


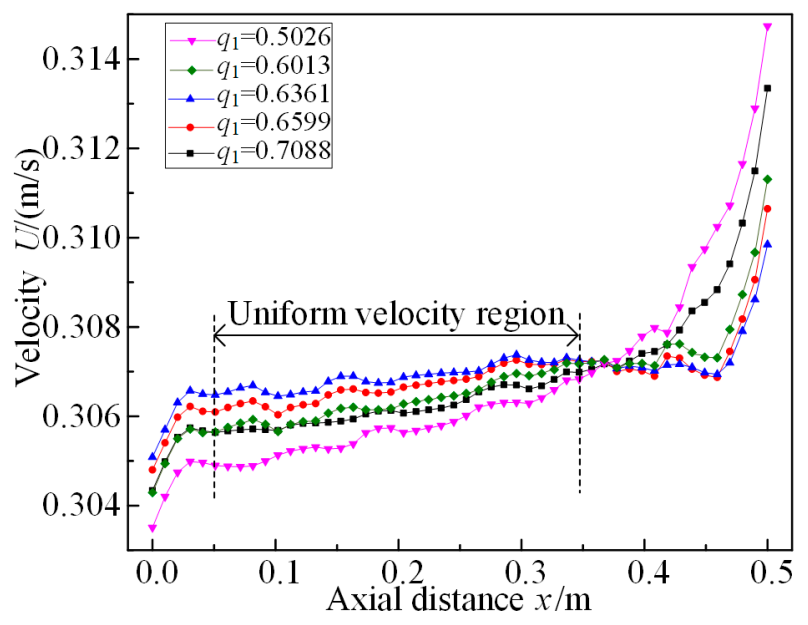

Figure 9. The velocity distribution of the fluid field from the inlet to the outlet of the test section when the honeycomb has different porosities $\left(q_{1}\right)$.
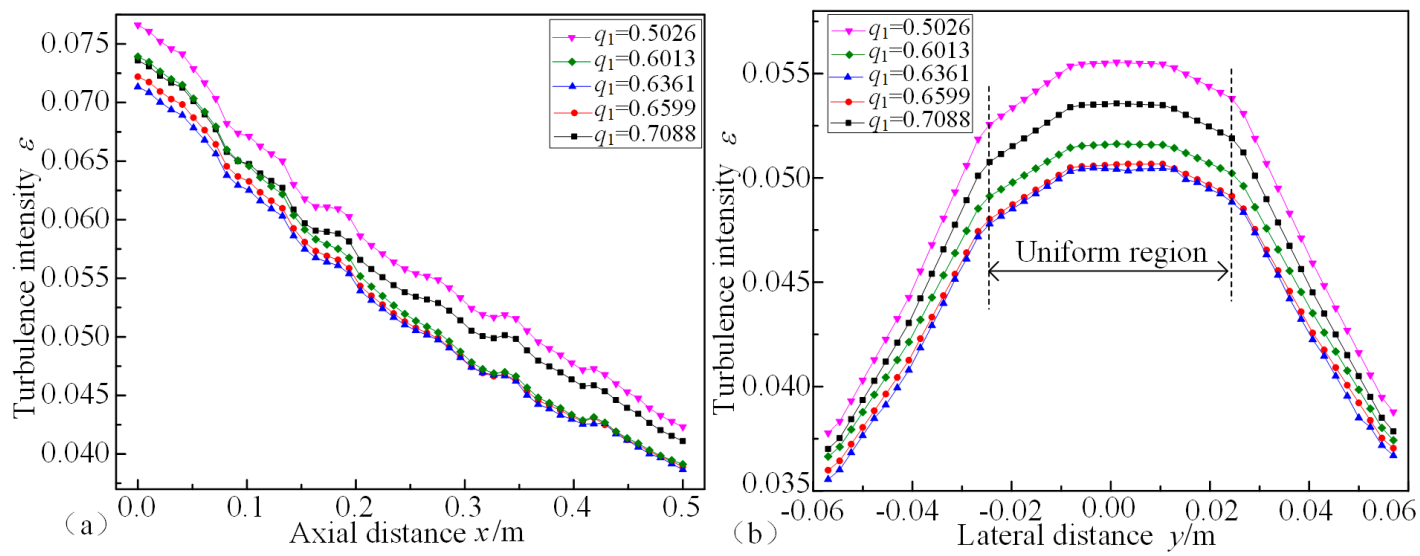

Figure 10. The distribution characteristics of the turbulence intensity when the honeycomb with different porosities is used: (a) along the axial direction and (b) along the lateral direction.

Table 4. The velocity inhomogeneity and average turbulence intensity of the fluid field in the test section when the honeycomb with different porosities is applied.

\begin{tabular}{cccccc}
\hline Porosity & $\mathbf{0 . 5 0 2 6}$ & $\mathbf{0 . 6 0 1 3}$ & $\mathbf{0 . 6 3 6 1}$ & $\mathbf{0 . 6 5 9 9}$ & $\mathbf{0 . 7 0 8 8}$ \\
\hline Velocity inhomogeneity $\beta$ & 1.1260 & 1.1251 & 1.1240 & 1.1247 & 1.1256 \\
Average turbulence intensity & 0.0527 & 0.0500 & 0.0491 & 0.0494 & 0.0511 \\
\hline
\end{tabular}

Figure 11 shows the turbulence intensity contours of the entrance cross-section, middle cross-section and exit cross-section of the test section when the honeycomb with different porosities is selected. As can be observed, the turbulence intensity gradually decreases from the entrance cross-section to the exit, and the turbulence intensity gradually increases from both sides to the middle and from the bottom to the free surface. Besides, by comparing the results under different conditions, it can be concluded that, when the porosity of the honeycomb is 0.6361 , a better fluid field quality of the test section can be obtained. As a large porosity can reduce the damping performance of the honeycomb, and a small porosity can weaken the rectification effect. In order to achieve the required fluid field characteristics in the test section, the honeycomb with a moderate porosity should be selected. In this work, the honeycomb with a porosity of 0.6361 was selected for the designed circulating water channel. 


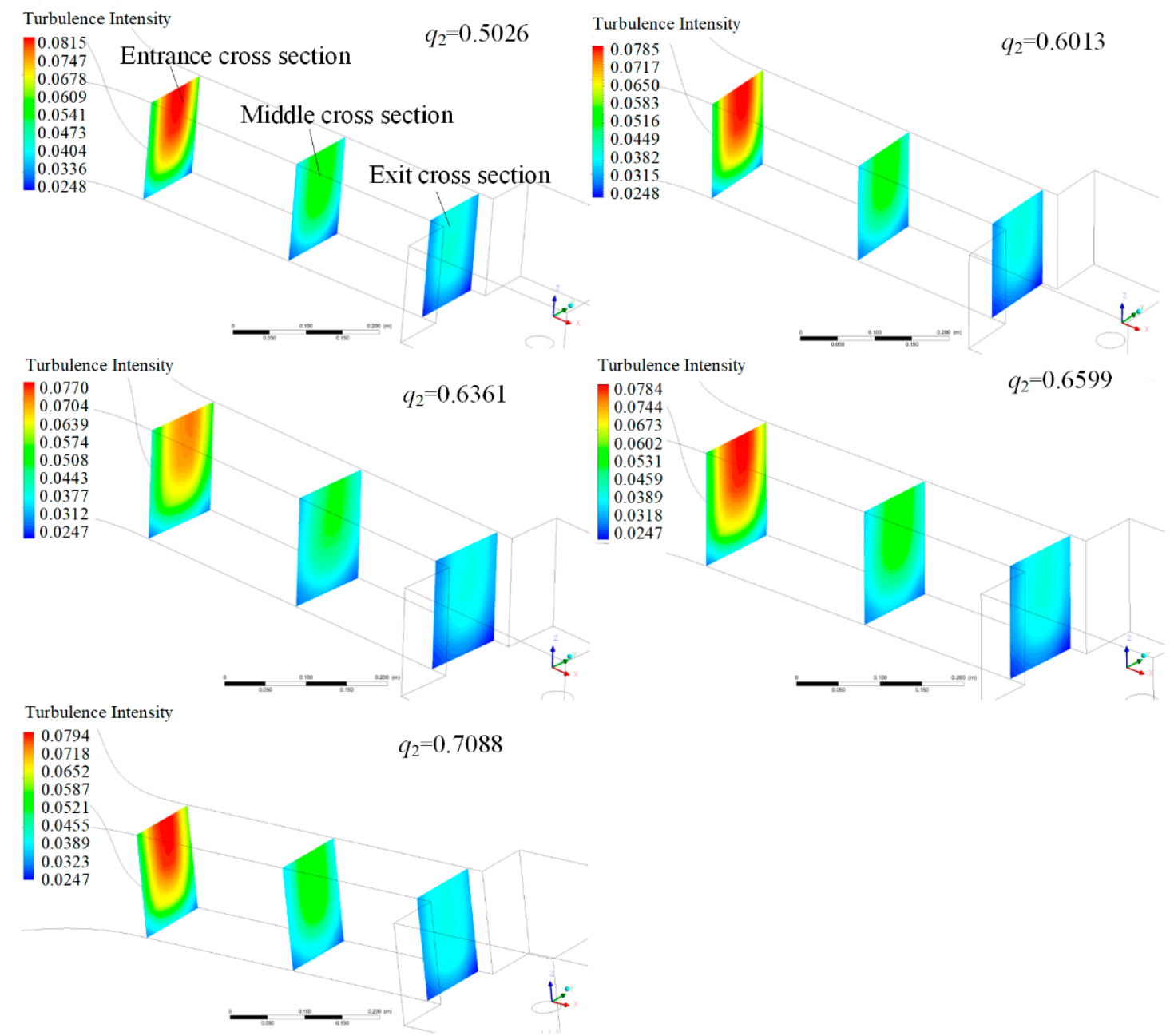

Figure 11. The turbulence intensity contours when the honeycomb with different porosities is selected. $\left(q_{2}\right)$ : screen porosities.

\subsection{Influences of the Screens}

When the fluid flows through the screen, the small-scale vortexes can be further broken, and the turbulence intensity of the flow is further reduced [14]. In order to obtain the required flow characteristics of the test section, the influences of the layer number, porosity, and the spacing of the screens on the flow characteristics are studied.

\subsubsection{Influences of the Screen Layer $n$}

Figure 12 shows the velocity contours (on the left) and turbulence intensity contours (on the right) when applying the screen with different layers. It can be seen that a relatively uniform velocity distribution state can be obtained in a short distance when the fluid flows through the rectification section and the contraction section. Table 5 presents the results of velocity inhomogeneity and average turbulence intensity when applying the screen with different layers. It is visible that, with the increase of the number of screen layers, the velocity inhomogeneity and the average turbulence intensity of the fluid field in the test section are gradually reduced. However, too many layers of the screen will reduce the velocity magnitude of the test section. The results demonstrate that the three-layer screen can meet the requirements of turbulence suppression, which is consistent with the results obtained by Kulkarni et al. [19]. Therefore, a three-layer screen is used in the designed circulating water channel in this work. 


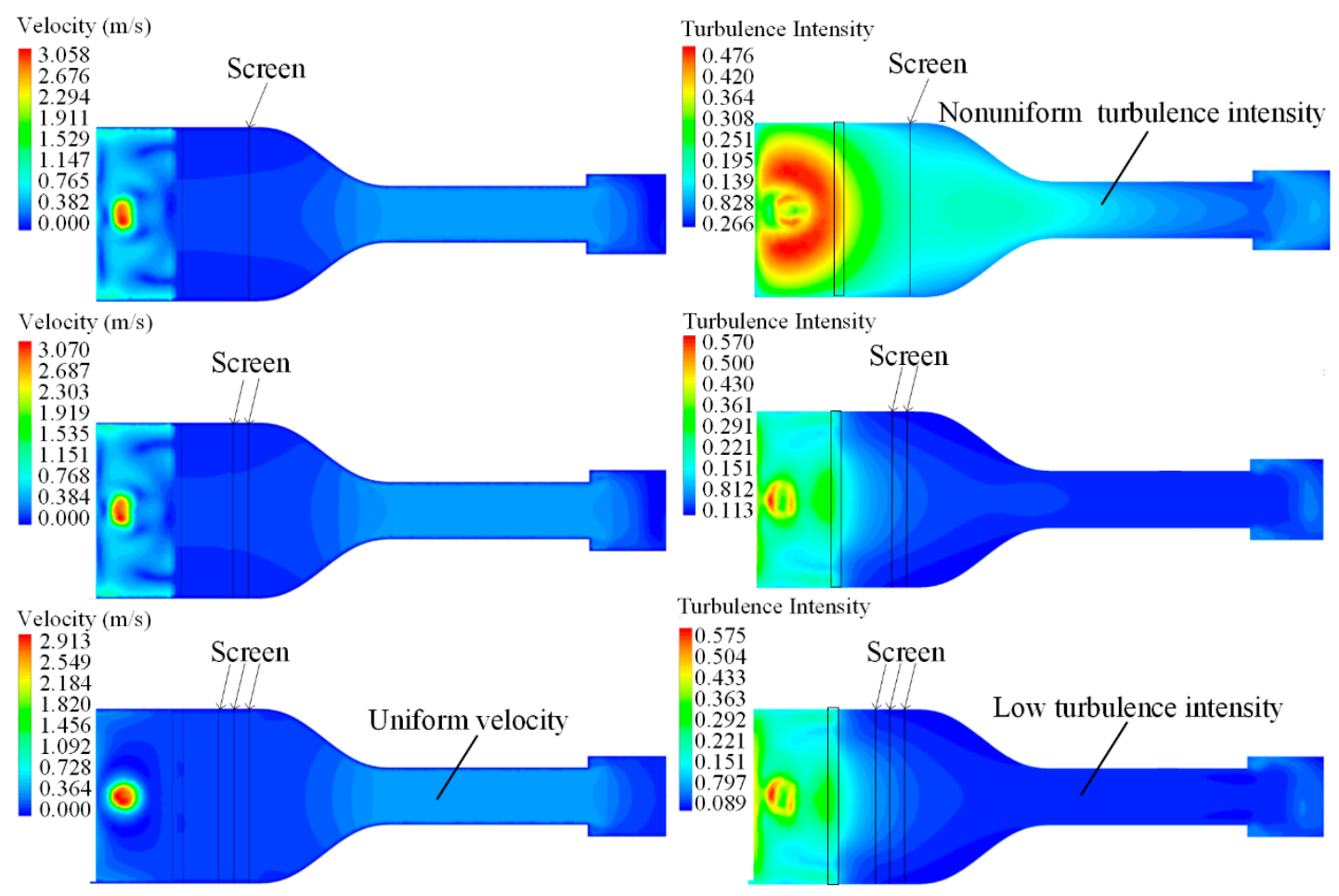

Figure 12. The velocity contours (on the left) and turbulence intensity contours (on the right) when applying a screen with different layers.

Table 5. The results of velocity inhomogeneity and average turbulence intensity when applying a screen with different layers.

\begin{tabular}{cccc}
\hline & One-Layer & Two-Layer & Three-Layer \\
\hline Velocity inhomogeneity $\beta$ & 1.1652 & 1.1521 & 1.1240 \\
Average turbulence intensity & 0.0984 & 0.0524 & 0.0491 \\
\hline
\end{tabular}

\subsubsection{Influence of the Screen Porosity $q_{2}$}

When the screen with a small porosity is used, a lower turbulence intensity can be obtained, as well as a large friction loss. For the screen used in a water channel for rectification, the porosity is generally greater than 0.5 [30]. Figure 13 shows the velocity distribution characteristics of the fluid field when the screen has different porosities. Figure 14 displays the distribution results of the turbulence intensity along the axial direction and the lateral direction when the screens with different porosities are used. It can be seen that, with the increase of the porosity of the screen, the velocity fluctuation and turbulence intensity of the fluid field in the test section first decrease and then increase. 


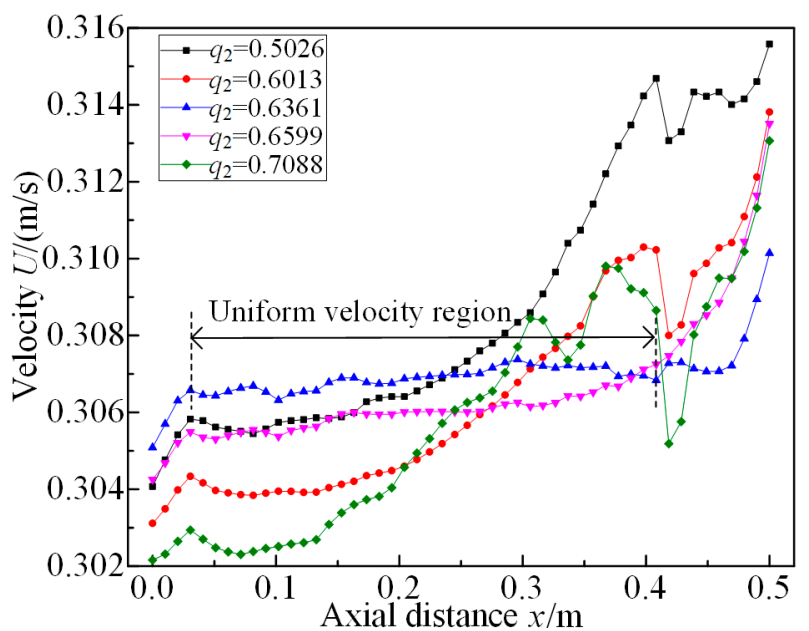

Figure 13. The velocity distribution characteristics of the fluid field when the screen has different porosities.
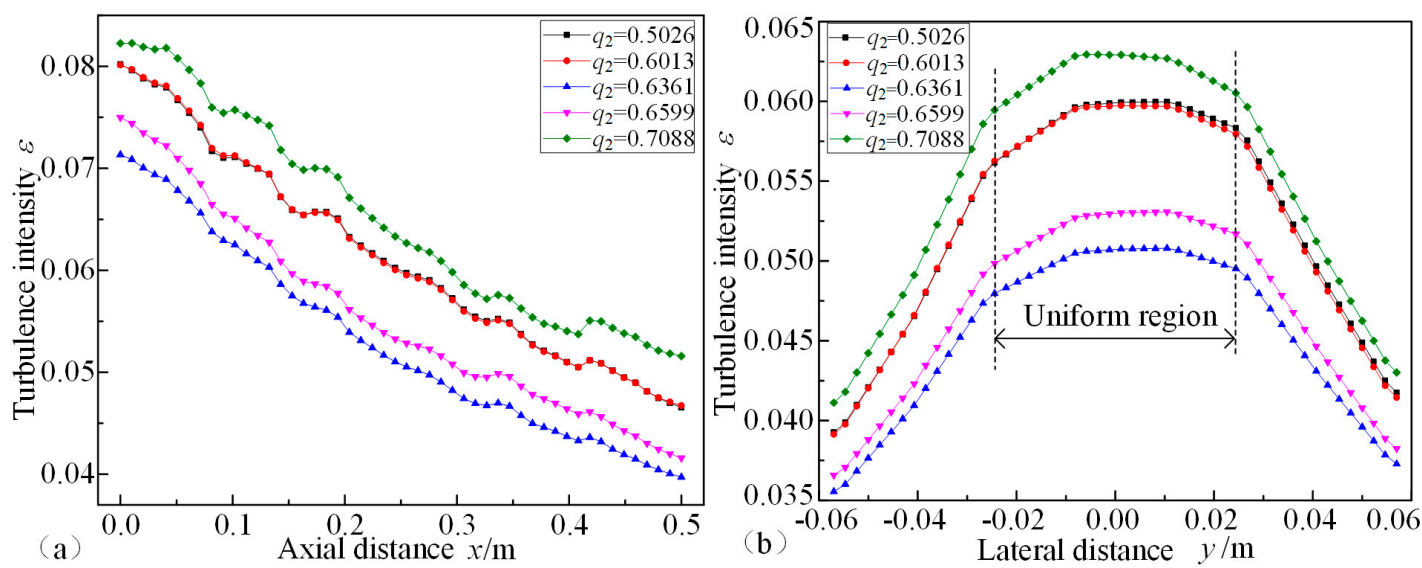

Figure 14. The distribution of the turbulence intensity when the screens with different porosities are used: (a) along the axial direction and (b) along the lateral direction.

Table 6 shows the velocity inhomogeneity and average turbulence intensity of the test section when the screens with different porosities are selected, and the pressure distribution contours are illustrated in Figure 15. It is noted that, with the increase of the porosity of the screen, the velocity fluctuation, average turbulence intensity, and pressure uniformity of the flow in the test section decrease first and, then, increase. When the porosity of the screen is 0.6361 , better flow field characteristics of the test section and a lower energy loss can be obtained. Therefore, the screens with too-large or too-small porosities will reduce the flow quality of the test section. In this work, the screen with a porosity as 0.6361 was chosen.

Table 6. The velocity inhomogeneity and average turbulence intensity of the test section when the screens with different porosities are selected.

\begin{tabular}{cccccc}
\hline Porosity & $\mathbf{0 . 5 0 2 6}$ & $\mathbf{0 . 6 0 1 3}$ & $\mathbf{0 . 6 3 6 1}$ & $\mathbf{0 . 6 5 9 9}$ & $\mathbf{0 . 7 0 8 8}$ \\
\hline Velocity inhomogeneity $\beta$ & 1.1366 & 1.1300 & 1.1240 & 1.1262 & 1.1472 \\
Average turbulence intensity & 0.0567 & 0.0558 & 0.0491 & 0.0512 & 0.0585 \\
\hline
\end{tabular}




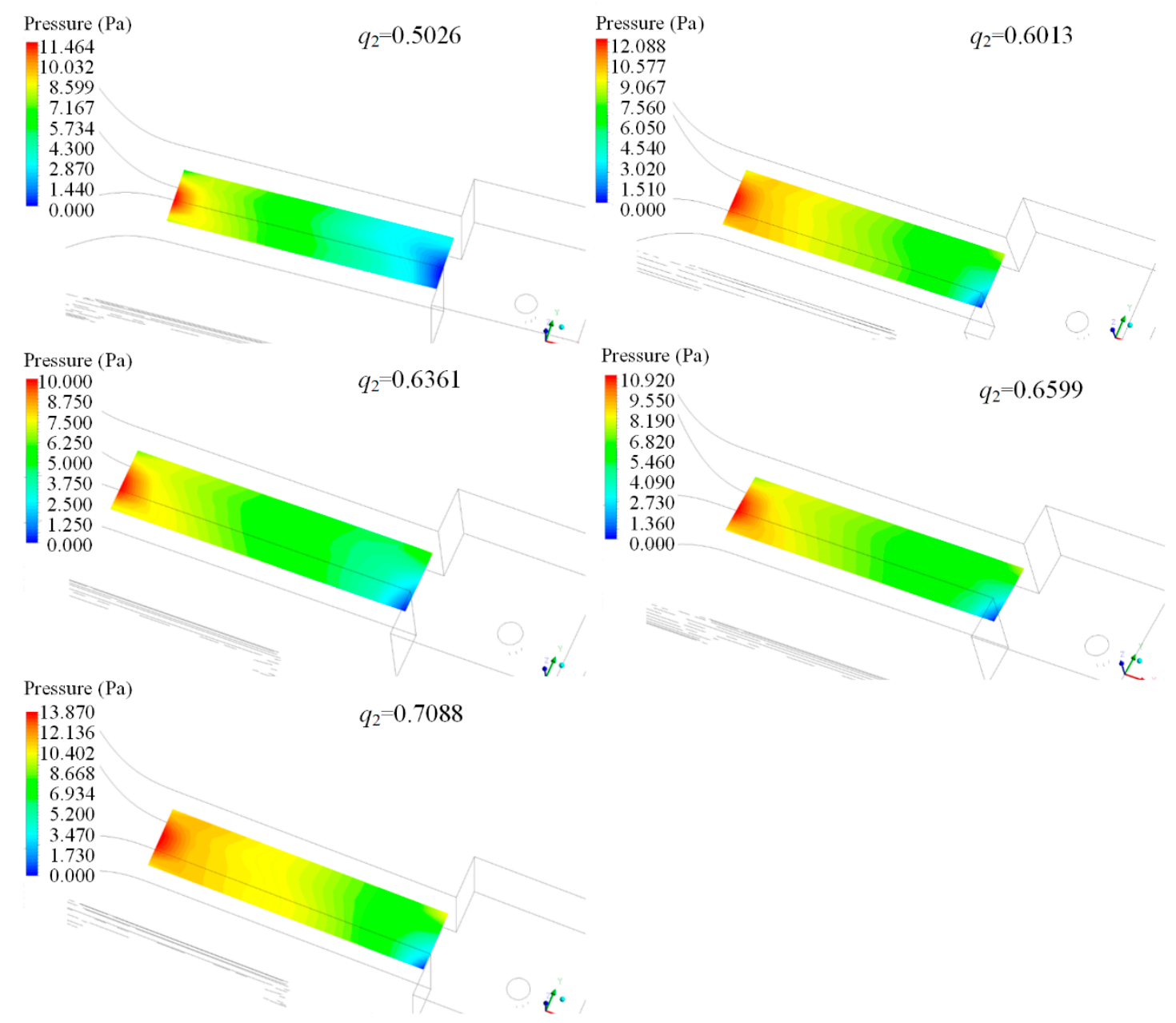

Figure 15. The pressure distribution contours when the screens with different porosities are selected.

\subsubsection{Influences of Screen Spacing $d$}

Three-layer screens with the porosity of 0.6361 are used for rectification. The turbulence intensity contours of the cross-sections at different locations are shown in Figure 16, and the maximum and minimum turbulence intensity values corresponding to each section are given. As can be seen, the turbulence intensity of the fluid field gradually decreases after the rectification of the honeycomb and screen, and with the increase of the spacing between the screens, the turbulence intensity of the test section decreases first and, then, increases.

Figures 17 and 18 show the flow characteristics of the test section when the screens are arranged at different spacings. It can be seen that screens with too-large or small spacings will cause an increase of the velocity fluctuation intensity in the test section. The turbulence intensity gradually decreases along the axial direction and gradually increases from both sides to the middle along the lateral direction. Accordingly, the results of the velocity inhomogeneity and average turbulence intensity in the test section are given in Table 7 . With the increase of the spacing between the screens, the velocity inhomogeneity and average turbulence intensity of the fluid field in the test section all first decrease and, then, increase. Therefore, the spacing between the screens should be moderate. In this work, $50 \mathrm{~mm}$ is selected as the screen spacing to obtain the required flow characteristics. 


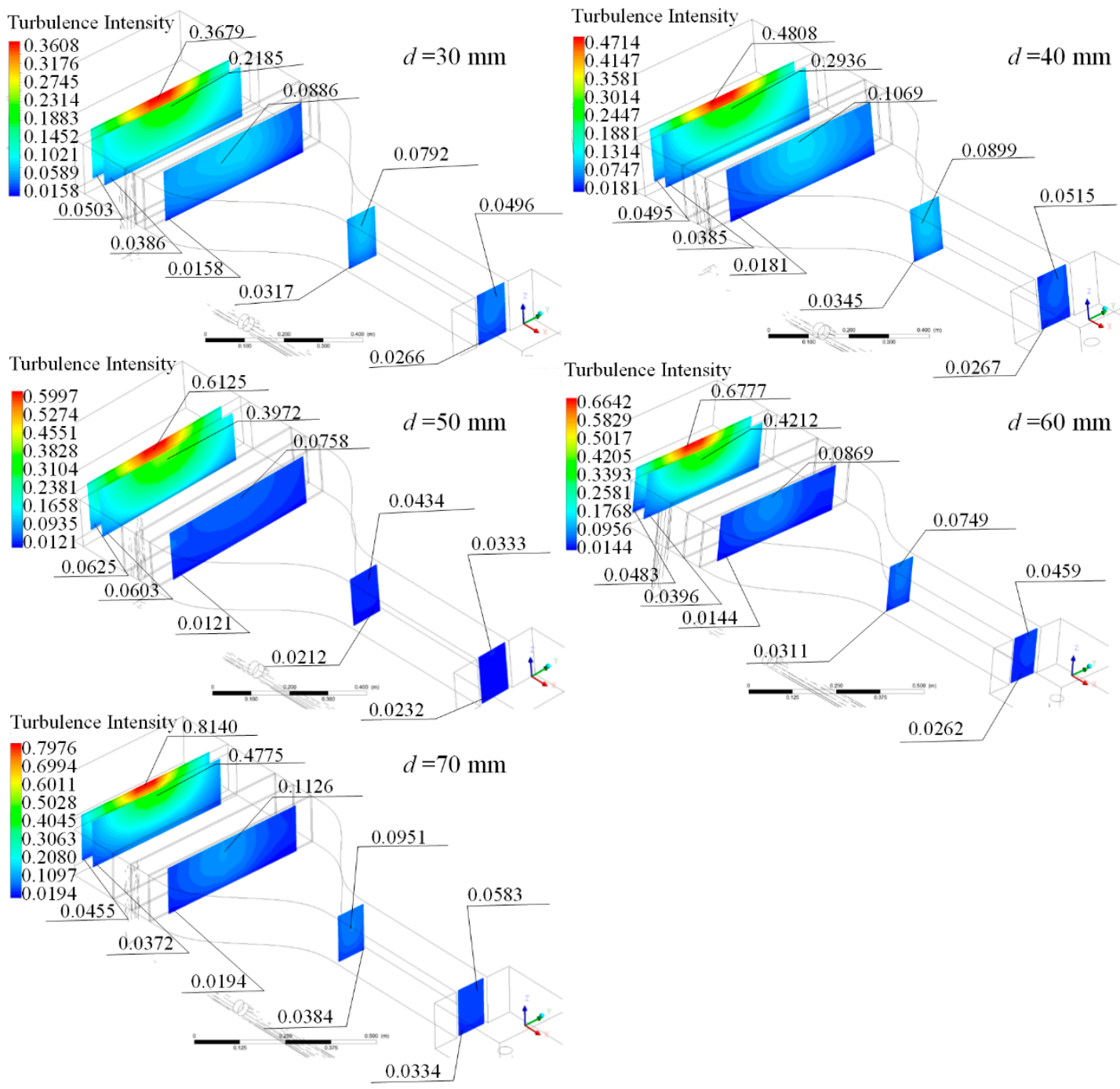

Figure 16. The turbulence intensity contours of the cross-sections at different locations.

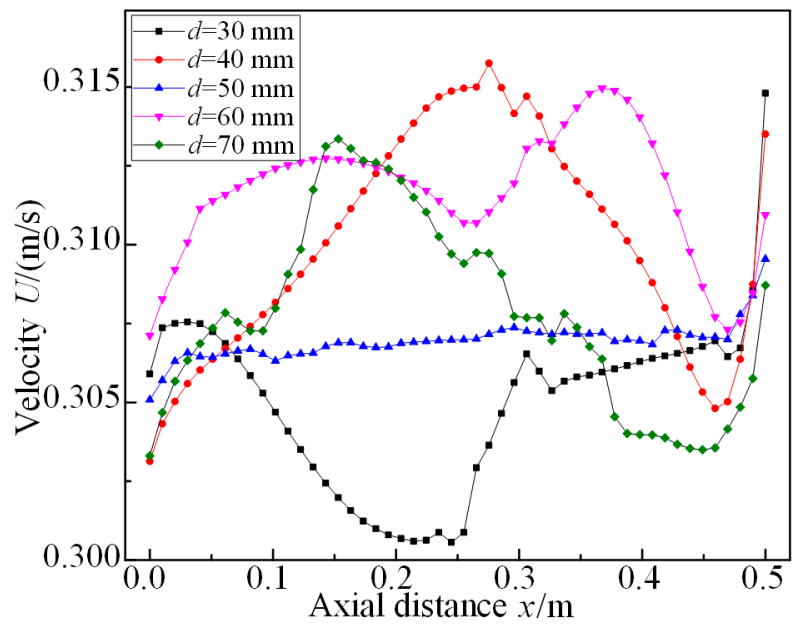

Figure 17. The velocity distribution characteristics of the fluid field when the screens are arranged at different spacings. 

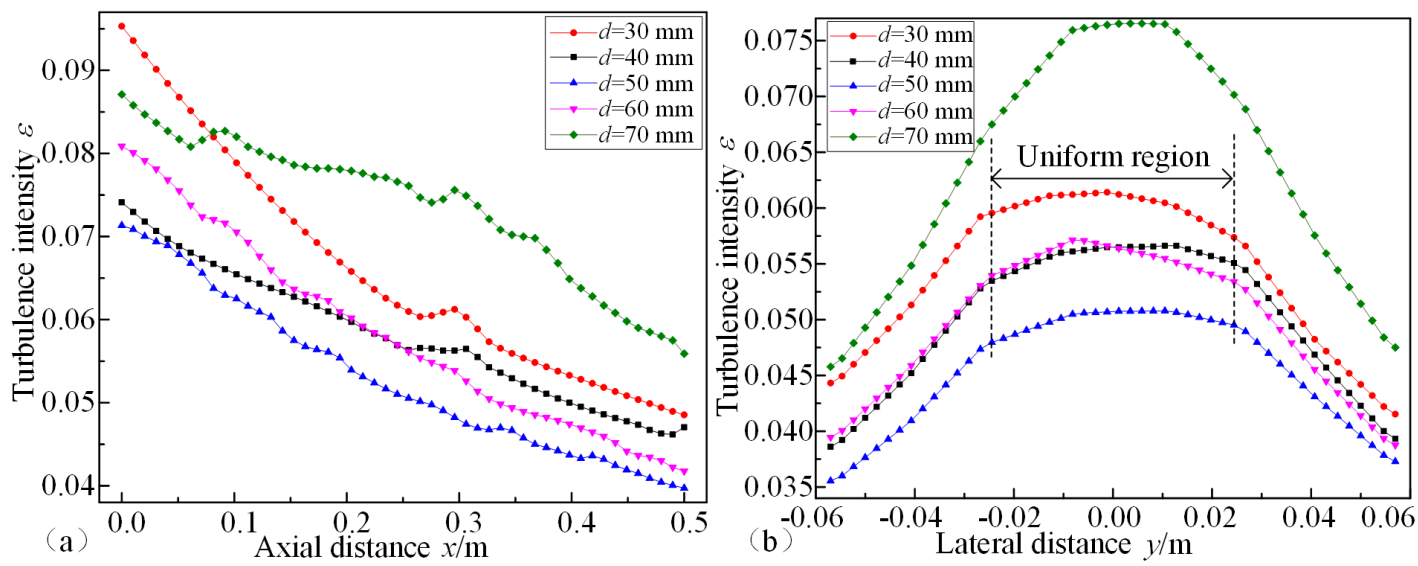

Figure 18. The distribution of the turbulence intensity along the axial direction and the lateral direction when the screens are arranged at different spacings: (a) along the axial direction, (b) along the lateral direction.

Table 7. The results of velocity inhomogeneity and average turbulence intensity when the screens are arranged at different spacings.

\begin{tabular}{cccccc}
\hline Spacing & $\mathbf{3 0} \mathbf{~ m m}$ & $\mathbf{4 0} \mathbf{~ m m}$ & $\mathbf{5 0 ~} \mathbf{m m}$ & $\mathbf{6 0} \mathbf{m m}$ & $\mathbf{7 0} \mathbf{m m}$ \\
\hline Velocity inhomogeneity $\beta$ & 1.2456 & 1.1327 & 1.1240 & 1.1684 & 1.1915 \\
Average turbulence intensity & 0.0603 & 0.0531 & 0.0491 & 0.0510 & 0.0658 \\
\hline
\end{tabular}

\subsection{The Influences of the Pumping Flow Rate $Q$}

For the circulating water channel, the flow velocity of the test section depends on the power of the water pump, which is generally described as the pumping flow rate $Q$. In order to meet the requirements of obtaining different flow velocities in the test section, the power of the pump should be adjustable. Figures 19 and 20 give the results of the flow characteristics when the pumping flow rate of the pump is different. Figure 19 shows the velocity and turbulence distribution characteristics along the axial and lateral directions of the test section. Figure 20 indicates the velocity and turbulence intensity contours of several cross-sections and gives the maximum velocity and turbulence intensity values. It can be seen that increasing the pumping flow rate can improve the flow velocity of the test section, while it will result in the increasing of the turbulence intensity. The turbulence intensity near the outlet of the test section is lower than that near the inlet. Besides, it can be seen from Figure 19 that, with the increase of the pumping flow rate, the turbulence intensity uniformity along the lateral direction gradually decreases, while the velocity uniformity at the corresponding area hardly changes. Therefore, when analyzing the hydrodynamic characteristics of the tested device along the axial direction, the device should be arranged near the outlet area of the test section; when analyzing the hydrodynamic characteristics of the tested device along the lateral direction, the pumping flow should be appropriately reduced to improve the uniformity of the turbulence intensity. 

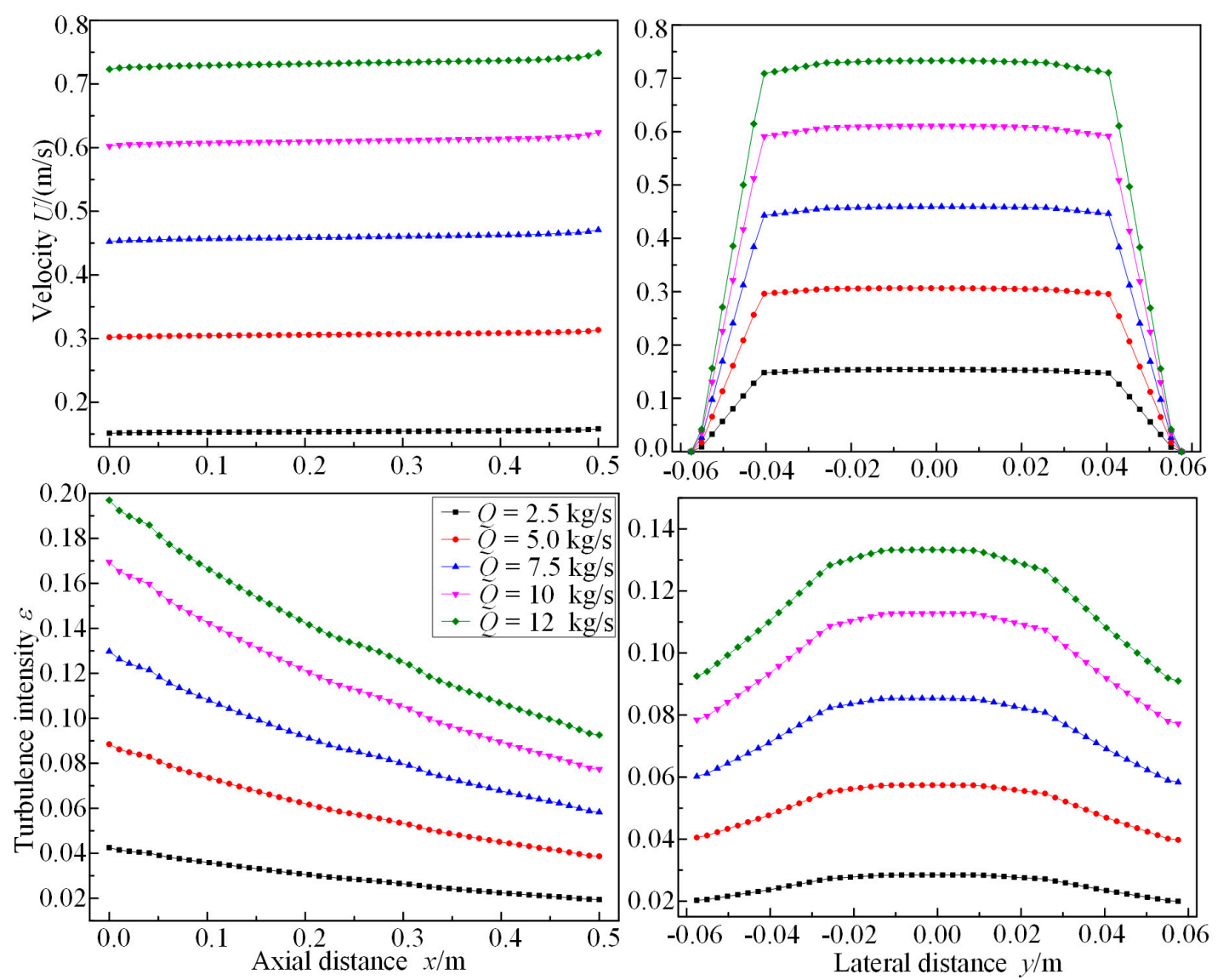

Figure 19. The velocity and turbulence intensity distribution characteristics at different pumping flow rates. $Q$ : pumping flow rate. 

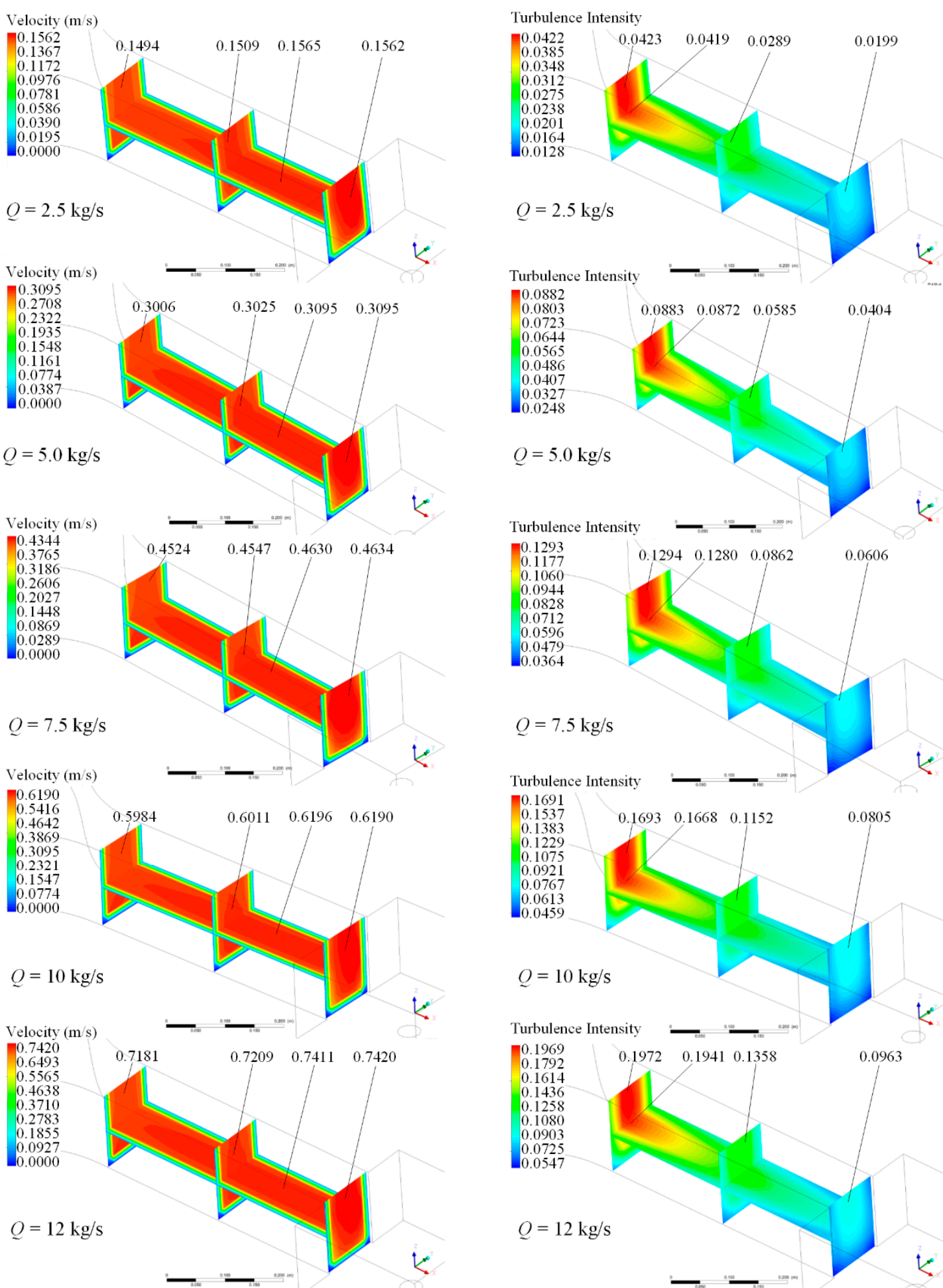

Figure 20. The velocity and turbulence intensity contours at different pumping flow rates.

\section{Experimental Results}

Based on the obtained optimization results, a small circulating water channel with a porous grid plate to achieve the fluid rectification is built. Considering the time and economic cost, the experimental verifications of the size optimization results are not carried out in this work. In order to verify the obtained analysis results, the flow characteristics of the test section, when the pumping flow rate is different, are obtained, as shown in Figure 21 The flow velocities at different positions of the test 
section are measured by the flow rate meter. Table 8 lists the relative errors between the experimental and simulation results. It can be seen that the experimental results are consistent with the obtained simulation analysis results, and the errors are within the acceptable range. It proves the validity and credibility of the simulation results.
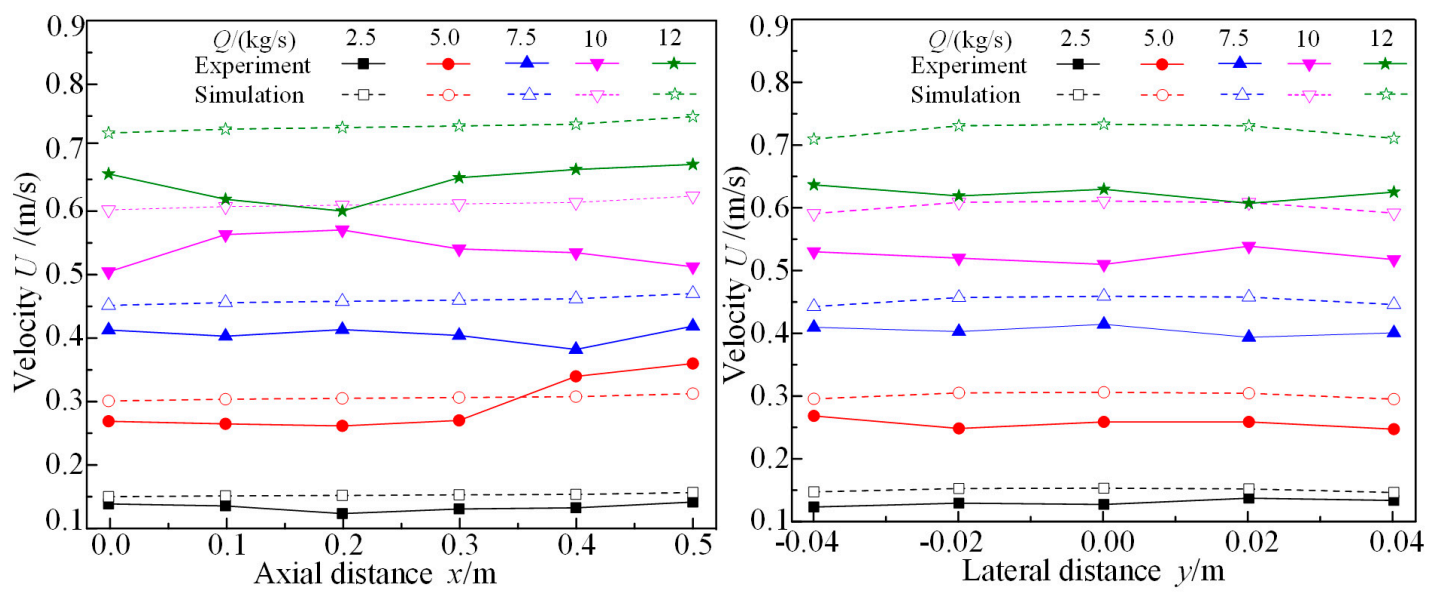

Figure 21. The velocities of the experiment and simulation at different pumping flow rates.

Table 8. The relative errors between the experimental and simulation results.

\begin{tabular}{ccccccc}
\hline \multicolumn{2}{c}{ Pumping Flow Rate } & $\mathbf{2 . 5} \mathbf{~ k g} / \mathbf{s}$ & $\mathbf{5} \mathbf{~ k g} / \mathbf{s}$ & $\mathbf{7 . 5} \mathbf{~ k g} / \mathbf{s}$ & $\mathbf{1 0 ~} \mathbf{~ g} / \mathbf{s}$ & $\mathbf{1 2} \mathbf{~ k g} / \mathbf{s}$ \\
\hline \multirow{5}{*}{ Axial distance $x / \mathrm{m}$} & 0 & $8.08 \%$ & $11.80 \%$ & $9.37 \%$ & $19.27 \%$ & $9.73 \%$ \\
& 0.1 & $11.53 \%$ & $14.58 \%$ & $13.09 \%$ & $7.81 \%$ & $17.81 \%$ \\
& 0.2 & $22.73 \%$ & $16.39 \%$ & $10.68 \%$ & $6.81 \%$ & $21.85 \%$ \\
& 0.3 & $16.66 \%$ & $13.24 \%$ & $13.69 \%$ & $13.08 \%$ & $12.43 \%$ \\
& 0.4 & $15.80 \%$ & $9.39 \%$ & $20.78 \%$ & $14.79 \%$ & $10.66 \%$ \\
Lateral distance $y / \mathrm{m}$ & 0.5 & $10.48 \%$ & $13.12 \%$ & $12.15 \%$ & $21.66 \%$ & $11.13 \%$ \\
\hline & -0.04 & $19.33 \%$ & $10.09 \%$ & $8.05 \%$ & $11.48 \%$ & $11.38 \%$ \\
& -0.02 & $17.99 \%$ & $22.77 \%$ & $13.43 \%$ & $17.05 \%$ & $18.03 \%$ \\
& 0 & $20.18 \%$ & $18.21 \%$ & $10.75 \%$ & $19.75 \%$ & $16.45 \%$ \\
& 0.02 & $10.64 \%$ & $17.55 \%$ & $16.24 \%$ & $12.93 \%$ & $20.33 \%$ \\
& 0.04 & $9.57 \%$ & $19.23 \%$ & $11.27 \%$ & $14.29 \%$ & $13.68 \%$ \\
\hline
\end{tabular}

\section{Conclusions}

A circulating water channel, which can reduce the turbulence by porous grid plates for the hydrodynamic characteristic analysis of a small device, is designed. In order to satisfy the requirements of obtaining the high-quality flow characteristics of the test section, the influences of the key parameters of the designed circulating water channel and the pump power on the flow characteristics of the test section are studied. The relationships between the porosity and the resistance coefficients (viscosity and resistance coefficient) are obtained. The influences of the thickness and porosity of the honeycomb; the layer number, porosity, and screen spacing of the screen; and the pumping flow rate on the velocity inhomogeneity and turbulence intensity of the test section are achieved. In this work, the turbulence intensity of the fluid field in the test section can be restrained to about 0.0491 .

With the increase of the thickness of the honeycomb and the spacing between the screens, the velocity inhomogeneity and the average turbulence intensity decrease first to the valley value and, then, increase. In order to obtain the uniform and low turbulence intensity flow characteristics of the test section, intermediate values of the thickness of the honeycomb and the spacing between the screens should be selected. Similarly, with the increase of the porosity of the honeycomb or screen, the velocity inhomogeneity and average turbulence intensity of the test section first decrease and, then, increase - that is to say, too much or little porosity of the porous grid plate will weaken the rectification performance. The increase of the screen layer number will lead to the decrease 
of the velocity inhomogeneity and the average turbulence intensity in the test section. However, too many layers of the screen will reduce the velocity of the test section. The analysis results show that the three-layer screen can satisfy the requirements of turbulence suppression. When studying the hydrodynamic characteristics along the axial direction of the tested device, the tested device should be arranged near the outlet area of the test section; when analyzing the hydrodynamic characteristics along the lateral direction of the tested device, the pumping flow rate should be appropriately reduced to improve the uniformity of the turbulence intensity. Based on the obtained optimization results, a small circulating water channel is built. Experiments are carried out, and the experimental results are consistent with the obtained analysis results, which prove the validity of the obtained results. This work can provide important references for the designing of a circulating water channel that is applied to test the hydrodynamic characteristics of a small underwater device.

Author Contributions: Methodology, L.Z.; validation, L.Z.; resources, L.Z.; data curation, L.Z.; writing—original draft preparation, L.Z.; writing-review and editing, L.Z.; visualization, L.Z.; supervision, X.S.; project administration, X.S.; and funding acquisition, T.X. All authors have read and agreed to the published version of the manuscript.

Funding: This study was funded in part by the National Natural Science Foundation of China (No. 51677043).

Conflicts of Interest: The authors declare no conflicts of interest.

\section{References}

1. Elbing, B.R.; Daniel, L.; Farsiani, Y.; Petrin, C.E. Design and Validation of a Recirculating, High-Reynolds Number Water Tunnel. J. Fluids Eng. 2018, 140, 081102. [CrossRef]

2. Park, J.T.; Cutbirth, J.M.; Brewer, W.H. Experimental Methods for Hydrodynamic Characterization of a Very Large Water Tunnel. J. Fluids Eng. 2005, 127, 1210-1214. [CrossRef]

3. Farsiani, Y.; Elbing, B.R. Characterization of the Custom-Designed, High Reynolds Number Water Tunnel. In Proceedings of the ASME 2016 Fluids Engineering Division Summer Meeting collocated with the ASME 2016 Heat Transfer Summer Conference and the ASME 2016 14th International Conference on Nanochannels, Microchannels, and Minichannels. Volume 2, Fora: Advances in Fluids Engineering Education; Cavitation and Multiphase Flow, Fluid Measurements and Instrumentation, Washington, DC, USA, 10-14 July 2016. [CrossRef]

4. Su, Y.-X. Flow analysis and design of three-dimensional wind tunnel contractions. AIAA J. 1991, 29, $1912-1920$. [CrossRef]

5. Leifsson, L.; Koziel, S. Simulation-driven design of low-speed wind tunnel contraction. J. Comput. Sci. 2015, 7, 1-12. [CrossRef]

6. Derbunovich, G.I.; Zemskaya, A.S.; Repik, E.U.; Sosedko, Y.P. Effect of flow contraction on the level of turbulence. Fluid Dyn. 1987, 22, 289-294. [CrossRef]

7. Morel, T. Comprehensive Design of Axisymmetric Wind Tunnel Contractions. J. Fluids Eng. 1975, 97, $225-233$. [CrossRef]

8. Bell, J.H.; Mehta, R.D. Contraction Design for Small Low-Speed Wind Tunnels; JIAA TR-84; NASA: Stanford, CA, USA, 1988.

9. Hasselmann, K.; Reinker, F.; Wiesche, S.A.D.; Kenig, E.Y. Numerical optimization of a piece-wise conical contraction zone of a high-pressure wind tunnel. In Proceedings of the ASME/JSME/KSME 2015 Joint Fluids Engineering Conference, Seoul, Korea, 26-31 July 2015.

10. Zhou, G.; Wang, J.-D.; Chen, H.-S.; Chen, D.-R. Optimized design of the contraction in a minitype high-speed water-tunnel. J. Ship Mech. 2009, 13, 513-521.

11. Azizi, F.; Al Taweel, A. Hydrodynamics of Liquid Flow Through Screens and Screen-Type Static Mixers. Chem. Eng. Commun. 2011, 198, 726-742. [CrossRef]

12. Lumley, J.L.; McMahon, J.F. Reducing Water Tunnel Turbulence by Means of a Honeycomb. J. Basic Eng. 1967, 89, 764-770. [CrossRef]

13. Loehrke, R.I.; Nagib, H.M. Control of Free-Stream Turbulence by Means of Honeycombs: A Balance Between Suppression and Generation. J. Fluids Eng. 1976, 98, 342-351. [CrossRef] 
14. Reshotko, E.; Saric, W.; Nagib, H. Flow quality issues for large wind tunnels. In Proceedings of the 35th Aerospace Sciences Meeting and Exhibit, Reno, NV, USA, 6-9 January 1997. [CrossRef]

15. Mikhailova, N.P.; Repik, E.U.; Sosedko, Y.P. Optimal control of free-stream turbulence intensity by means of honeycombs. Fluid Dyn. 1994, 29, 429-437. [CrossRef]

16. Derbunovich, G.I.; Zemskaia, A.S.; Repik, E.U.; Sosedko, I.P. Optimal conditions for controlling the intensity of turbulent flow by means of screens. Mech. Nonunif. Turbul. Flows 1989, A91-23901, 8-34.

17. Derbunovich, G.I.; Zemskaya, A.S.; Repik, E.U.; Sosedko, Y.P. Optimum conditions of turbulence reduction with screens. Fluid Dyn. 1993, 28, 138-144. [CrossRef]

18. Scheiman, J.; Brooks, J. A comparison of experimental and theoretical turbulence reduction from screens, honeycomb and honeycomb-screen combinations. In Proceedings of the 11th Aerodynamic Testing Conference, Colorado Springs, CO, USA, 18-20 March 1980; pp. 638-643. [CrossRef]

19. Kulkarni, V.; Sahoo, N.; Chavan, S.D. Simulation of honeycomb-screen combinations for turbulence management in a subsonic wind tunnel. J. Wind. Eng. Ind. Aerodyn. 2011, 99, 37-45. [CrossRef]

20. Farell, C.; Youssef, S. Experiments on Turbulence Management Using Screens and Honeycombs. J. Fluids Eng. 1996, 118, 26-32. [CrossRef]

21. Robbins, B.E. Water Tunnel Turbulence Measurements Behind a Honeycomb. J. Hydronaut. 1978, 12, $122-128$. [CrossRef]

22. Okolo, P.; Zhao, K.; Kennedy, J.; Bennett, G.J. Numerical assessment of flow control capabilities of three dimensional woven wire mesh screens. Eur. J. Mech. B/Fluids 2019, 76, 259-271. [CrossRef]

23. Jakubowski, M.; Antonowicz, A.; Janowicz, M.; Sterczyńska, M.; Piepiórka-Stepuk, J.; Poreda, A. An assessment of the potential of shadow sizing analysis and Particle Image Velocimetry (PIV) to characterise hot trub morphology. J. Food Eng. 2016, 173, 34-41. [CrossRef]

24. Sterczyńska, M.; Stachnik, M.; Poreda, A.; Stepuk, J.P.; Zdaniewicz, M.; Jakubowski, M. The improvement of flow conditions in a whirlpool with a modified bottom: An experimental study based on particle image velocimetry (PIV). J. Food. Eng. 2020. [CrossRef]

25. Mikhail, M.N. Optimum Design of Wind Tunnel Contractions. AIAA J. 1979, 17, 471-477. [CrossRef]

26. Purdy, H.D. Model. Experiments for the Design of a Sixty Inch Water Tunnel; St. Anthony Falls Hydraulic Laboratory University of Minnesota: Minneapolis, MN, USA, 1948.

27. Fang, F.-M.; Chen, J.; Hong, Y. Experimental and analytical evaluation of flow in a square-to-square wind tunnel contraction. J. Wind. Eng. Ind. Aerodyn. 2001, 89, 247-262. [CrossRef]

28. Stachnik, M.; Jakubowski, M. Multiphase model of flow and separation phases in a whirlpool: Advanced simulation and phenomena visualization approach. J. Food Eng. 2020, 274, 109846. [CrossRef]

29. Grumet, A.; Welder, W.; Peavey, C. Navier-Stokes Analysis of NWTC Back Leg Diffuser. In Proceedings of the 35th Aerospace Sciences Meeting and Exhibit, Reno, NV, USA, 6-9 January 1997. [CrossRef]

30. Mehta, R.D. Turbulent boundary layer perturbed by a screen. AIAA J. 1985, 23, 1335-1342. [CrossRef] 